\title{
DOE|PC/ $95216--12$ \\ REDUCTION OF INHERENT MERCURY EMISSIONS IN PC COMBUSTION
}

DOE Grant No. DE-FG22-95PC95216

Period of Performance: June 29, 1995 to June 28, 1998

Semi-Annual Technical Progress Report No. 2

Period Covered by Report: January 1, 1996 to June 30, 1996

Prepared by:

JOHN C. KRAMLICH

REBECCA N. SLIGER

DAVID J. GOING

Department of Mechanical Engineering

Box 352600

University of Washington

Seattle, Washington 98195-2600

Prepared for:

DOCUMENT CONTROL CENTER

U.S. Department of Energy

Pittsburgh Energy Technology Center

P. O. Box 10940, MS 921-118

Pittsburgh, Pennsylvania 15236-0940

DOE Program Manager: Perry D. Bergman

DOE Contracting Officer's Representative: John R. Columbia Award Amount: \$197,089

Date Submitted: August 19, 1996

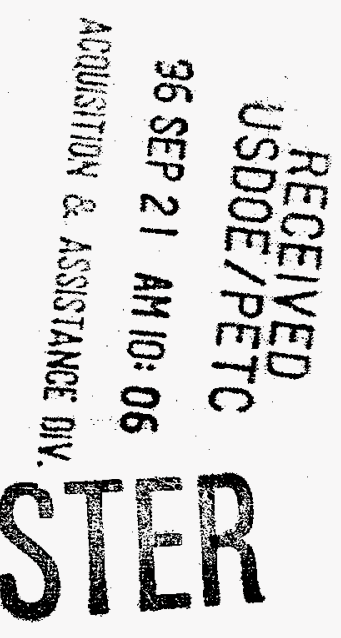




\section{DISCLAIMER}

This report was prepared as an account of work sponsored by an agency of the United States Government. Neither the United States Government nor any agency thereof, nor any of their employees, make any warranty, express or implied, or assumes any legal liability or responsibility for the accuracy, completeness, or usefulness of any information, apparatus, product, or process disclosed, or represents that its use would not infringe privately owned rights. Reference herein to any specific commercial product, process, or service by trade name, trademark, manufacturer, or otherwise does not necessarily constitute or imply its endorsement, recommendation, or favoring by the United States Government or any agency thereof. The views and opinions of authors expressed herein do not necessarily state or reflect those of the United States Government or any agency thereof. 


\section{DISCLAMMER}

Portions of this document may be illegible in electronic image products. Images are produced from the best available original document. 


\section{Introduction and Objectives}

The 1990 Clean Air Act Amendments handed the utility industry a major challenge for the coming years. The legislation requires that the U.S. Environmental Protection Agency set emission standards for the 189 compounds or compound families identified in the act as air toxics. Evaluations by EPRI have identified 37 of these species as concerns in power generation (Feldman et al., 1993). These include toxic organics, $\mathrm{HCl}, \mathrm{HF}$, and trace metals. Metals frequently mentioned include: arsenic, barium, beryllium, cadmium, chromium, cobalt, copper, lead, manganese, mercury, molybdenum, nickel, selenium and vanadium. The organic compounds considered include formaldehyde, various aromatic hydrocarbons, and chlorine-substituted dioxins and furans.

The EPA initially addressed the problem of estimating emissions through literature values of emission factors (Radian, 1989). The major weaknesses of this approach include the broad range of trace element content in coal, the wide variety of boiler design and operating conditions, and the variable performance of pollution control equipment, assuming any exists (Chow and Torrens, 1994). In response to this perceived weakness in the emission database, EPRI and DOE have performed comprehensive studies of power plant emissions. Although ongoing, critical trends have emerged from these data that provide direction.

First, the emissions of toxic organic compounds have generally been below detection limits. This is a consequence of high combustion temperatures sustained over long periods of time. In addition, chlorine levels are usually so low in coals that it becomes difficult to synthesize the toxic chlorinated dioxin cognators. Finally, the presence of $\mathrm{SO}_{2}$ from the fuel-sulfur has been shown to interfere with the downstream dioxin formation process. In any case, toxic organic emissions are not perceived to be a major problem.

Measurements on the trace metals listed above generally show that over $90 \%$ of the initial elements present in the coal are collected with the bottom ash or the fly ash. These metal compounds have low volatility and condense out onto the existing fly ash, where they are collected by the fabric filter or the electrostatic precipitator (Chow and Torrens, 1994; Devito et al., 1994). However, the removal efficiencies do show considerable variability.

Only mercury and selenium generally show low removal efficiencies and correspondingly high emission factors. This is attributed to the high volatility of these elements in both their combined and uncombined forms. Rather than condensing onto fly ash particles, these species tend to stay in vapor phase, pass through the particulate control systems, and become emissions. The data show, however, wide variabilities in the emission indices of these two elements. Some forms of mercury (e.g., $\mathrm{Hg}^{++}$) appear to be less volatile than the element, and show a greater tendency to collect on the fly ash. The processes governing inherent mercury capture are not well understood. The reason for this wide variability in emissions is not well understood (Chow and Torrens, 1994). This is a concern because mercury and selenium appear to be the only two elements, beyond the traditional pollutants, that may become air toxic compliance problems for the utility industry. In recognition of this, there has already been substantial work on identifying ways of reducing emissions.

Ideas for post-flame mercury control have centered around existing air pollution control devices, or relatively simple modifications of these that improve their specific mercury performance. Much of this work was originally done to control toxic metals from MSW incineration, and it is now being reevaluated for the lower metals content of coal. One example is the hydrated lime spray dryer for $\mathrm{SO}_{2}$ control. The mercury removal of an unmodified spray dryer system is of the order of only $30-$ $50 \%$, but the addition of activated carbon in the flue gas leads to greater than $90 \%$ removal in some tests (Gleiser and Felsvang, 1994); not all results have shown such high efficiency, however (Chow and Torrens, 1994). Wet scrubbers are relatively effective against $\mathrm{Hg}^{++}$due to their low 
operating temperatures $\left(\mathrm{ca} .45^{\circ} \mathrm{C}\right)$, but still remove only $50-70 \%$ of elemental mercury (Meij, 1991). Dry sorbent injection has been tested at EPA (Gullett and Raghunathan, 1994).

At present, mercury emission compliance presents one of the major potential challenges raised by the Clean Air Act Amendments. Simple ways of controlling emissions have not been identified. The variability in the field data suggest that means exist to reduce inherent mercury emissions, if these can be identified and controlled. The key mechanisms appear to involve the oxidation of the mercury to $\mathrm{Hg}^{+}$, generally producing the less volatile $\mathrm{HgCl}_{2}$. A portion of this may condense on ash particles in time to be collected by cold-side particulate removal equipment.

This research focuses on identifying the rate-limiting steps associated with inherent mercury capture. Key areas are enhancement of mercury oxidation and providing a sufficient amount of an appropriate surface (e.g., ash aerosol) under the correct conditions to promote inherent capture.

\section{Technical Progress}

Work during the present quarter has focused on analytical setup and reactor modifications. As described in the previous progress report, the goal of the analytical system is to differentiate between $\mathrm{Hg}^{\circ}$ and $\mathrm{Hg}^{++}$. The method is based on EPA Method 29 (the multimetals train) with the following modifications:

- No filter is used since the initial experiments do not involve any solids.

- Since no solids are sampled, no attempt is made to guarantee isokinetic sampling.

- A water-cooled quartz probe is placed inside an uncooled stainless steel liner. No attempt is made to keep the sample hot before the impingers since no hot filtering is needed. Instead, the condensate from the probe and the probe wash are combined with the catch from the first two impingers.

Review of the recent literature and discussions with parties active in field sampling and analysis indicate some interferences in Method 29. Specifically, both $\mathrm{SO}_{2}$ and $\mathrm{Cl}_{2}$ are indicated as interfering with the speciation of $\mathrm{Hg}^{\circ} \mathrm{vs}$. $\mathrm{Hg}^{++}$. Both appear to allow a fraction of the $\mathrm{Hg}^{++}$catch to bypass the first impingers and become collected in the permanganate impingers. Although alternate solutions are proposed for the first two impingers (e.g., replacing $\mathrm{H}_{2} \mathrm{O}_{2}$ with $\mathrm{KCl}$ ), since neither $\mathrm{Cl}_{2}$ or $\mathrm{SO}_{2}$ are present in our samples, we are initially working with unmodified Method 29.

All analytical equipment has been received and set up, and quality assurance tests involving spiking of various concentrations of elemental and oxidized mercury are underway.

Figure 1 shows the furnace, and can be used as a guide to the modifications that are underway for the first series of experiments. The initial experimental test series examines the conditions that lead to the oxidation of $\mathrm{Hg}^{\circ}$ to $\mathrm{Hg}^{++}$under essentially isothermal conditions. An aqueous solution of mercuric acetate is introduced into the flame zone via a microatomizer. The high temperature of the flame zone provides complete breakdown of the acetate, and the reduction of the mercury to $\mathrm{Hg}^{\circ}$. At the throat of the furnace, quench air is added to reduce the gas temperature to the desired level. The $\mathrm{HCl}$ is also introduced at this point. The auxiliary heaters are used to hold the reaction temperature constant throughout the remainder of the furnace, up to the sampling point.

The only major hardware modification needed to the existing facility are as follows:

- Addition of the $\mathrm{Hg}(\mathrm{Ac})_{2}$ atomization system to center of the natural gas passage. 
- Increasing the capacity of the air metering system for the dilution air port.

- Addition of an $\mathrm{HCl}$ metering system for injection into the dilution air line.

A series of tests were performed to identify thermal conditions for this experimental series. Stable, isothermal temperature profiles ranging between 900 to $400^{\circ} \mathrm{C}$ were obtained by use of moderate firing on the upper backfire burners, and heavier firing of the lower backfire burners. Fortunately, the residence time remained nearly constant for all these tests since the higher density associated with the lower temperatures almost exactly compensated for the additional dilution gas flow needed to achieve the lower temperatures. Thus, for all temperatures the residence time was approximately 1 second at the furnace exit.

\section{Future Work}

Upon completion of the analytical check out, the initial test series will be run. This will consist of the measurement of mercury oxidation rates as a function of temperature, mercury concentration, $\mathrm{HCl}$ concentration, and residence time. The next series of experiments will examine the use of free radical promoters for the oxidation.

\section{References}

Chow, W. and I. M. Torrens: Managing power plant trace substances emissions: An overview. Proc. American Power Conference, Vol. 56-1, p. 427 (1994).

Devito, M., L. Rosendale, V. Conrad, and B. Jackson: Trace elements in coals and their emissions. Proc. American Power Conference, Vol. 56-1, p. 438 (1994).

Feldman, P. L., K. S. Kumar, and J. M. Quimby: Power 137(7), 48 (1993).

Gleiser, R. and K. Felsvang: Mercury emission reduction using activated carbon with spray dryer flue gas desulfurization. Proc. American Power Conference, Vol. 56-1, p. 452 (1994).

Gullett, B. K., and K. Raghunathan: Energy and Fuels 8, 1068 (1994).

Meij, R.: Water, Air, and Soil Pollut. 56, 21 (1991).

Radian Corporation: Estimating Air Toxics Emissions from Coal and Oil Combustion Sources. EPA Report 450/2-89-001 (1989). 


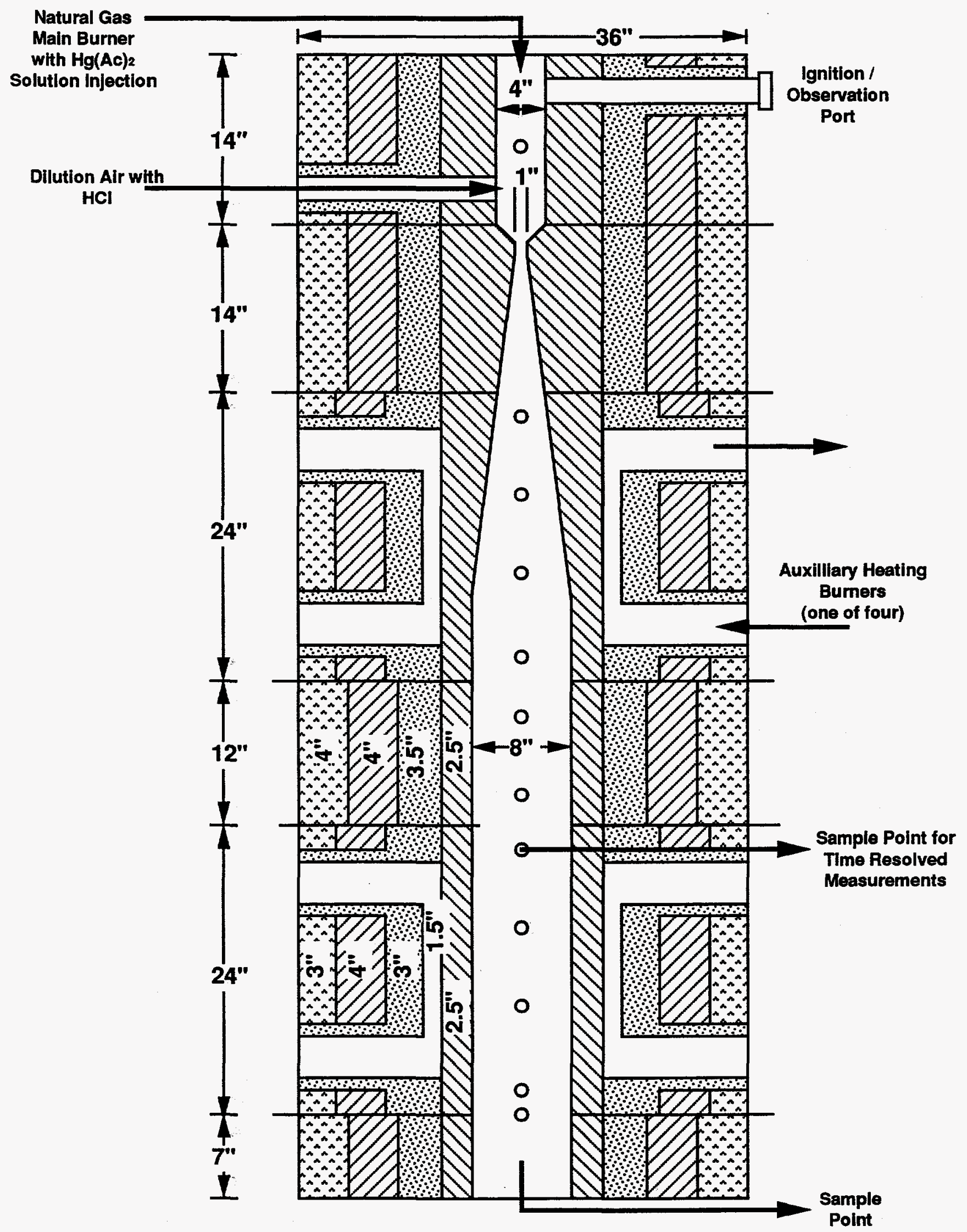

Figure 1. Reactor schematic showing modifications for the initial mercury studies. 